\title{
Experimental Study of Effects of Coflow Air and Partial Premixing on Liquid Petroleum Gas Flames
}

\author{
R. Sreenivasan, Sumit Kumar Koli, and Vasudevan Raghavan \\ Department of Mechanical Engineering, Indian Institute of Technology, Madras 600036, India \\ Correspondence should be addressed to Vasudevan Raghavan, raghavan@iitm.ac.in
}

Received 6 December 2011; Accepted 15 January 2012

Academic Editors: J. K. Brennan, I. I. El-Sharkawy, K. Khanafer, M. Manciu, and G. Polidori

Copyright () 2012 R. Sreenivasan et al. This is an open access article distributed under the Creative Commons Attribution License, which permits unrestricted use, distribution, and reproduction in any medium, provided the original work is properly cited.

Investigation of the influence of coflow and partial air premixing on liquid petroleum gas (LPG) flames in a lab-scale co-flow burner is presented. Primary air is supplied along with LPG in the inner core, and secondary air is supplied through the annulus region of the burner. Digital images are analyzed to study the flame shape, color, height, radius, and qualitative laminar flame speed. Concentrations of product gases and emission species are measured using a digital gas analyzer. Results indicate that in a dual air stream configuration, the partial premixing is optimum at $\%$ primary air value of around $45 \%$.

\section{Introduction}

Laminar nonpremixed and premixed flames have applications in several residential, commercial and industrial devices such as gas ranges, ovens, heating appliances, and burners. Both premixed and non-premixed laminar flame studies have been carried out employing a wide range of fuels and with even fuel mixtures. Both types of flames have their own advantages as well as disadvantages. For example, premixed flame produces less pollutant species, especially, least $\mathrm{CO}$ and soot. On the other hand, it has stability concerns, and it can produce more NO in higher flame temperature cases. Nonpremixed flame is quite stable over a wide range of operating parameters. However, it produces soot, nitrogen dioxide, and carbon monoxide and can result in less combustion efficiency in few cases. Partial premixing process would inherit the advantages of both premixed and diffusion flames. Therefore, partial premixing of reactants is gaining importance and is able to meet the rigorous emission standards enforced by different nations around the world. Based on the fuel, there exists a percentage of partial premixing, which can produce lesser emissions and also have higher stability. Hydrocarbon fuel flames have been studied exhaustively due to its usage in several practical devices. Liquefied petroleum gas (LPG) is used as the most feasible fuel in domestic sectors as well as in industrial applications. In India, the majority of the household burners utilize LPG as their fuel. LPG is nontoxic, noncorrosive, and free of tetra-ethyl lead, and it has higher octane rating. These features have resulted in its usage in transport sector also. When compared with natural gas and other fuels, LPG has higher calorific value. Because of its broad flammability limits, it has found its place in lean burn conditions. However, when compared with gasoline and other fuel oils, the equivalent LPG consumption is higher due to its less energy density. As a result, it is less economical and also can result in the formation of higher emissions.

Several studies are reported on LPG-air premixed and diffusion flames. However, the information available on partially premixed LPG-air flames is limited. A study on the flammability limits of LPG-air mixture was done experimentally by Mishra and Rehman [1]. Lower flammability limit (LFL) and upper flammability limit (UFL) for both upward and downward propagating flames were reported, and the influence of nitrogen dilution on the flammability limits was also studied [1]. Stability and emission in an LPG-air premixed coaxial jet flame burner under a wide range of operating conditions were studied by Mishra [2]. The effect of $\mathrm{H}_{2}$ addition on LPG- $\mathrm{H}_{2}$ jet diffusion flame with preheated reactants was experimentally investigated by Mishra and Kumar [3]. Reduction in the flame length with the addition of $\mathrm{H}_{2}$ due to the increased gas temperature was reported. Another parameter studied by them was the sootfree length fraction, which decreased with the an increase in reactant temperature. This was attributed to the reduction 


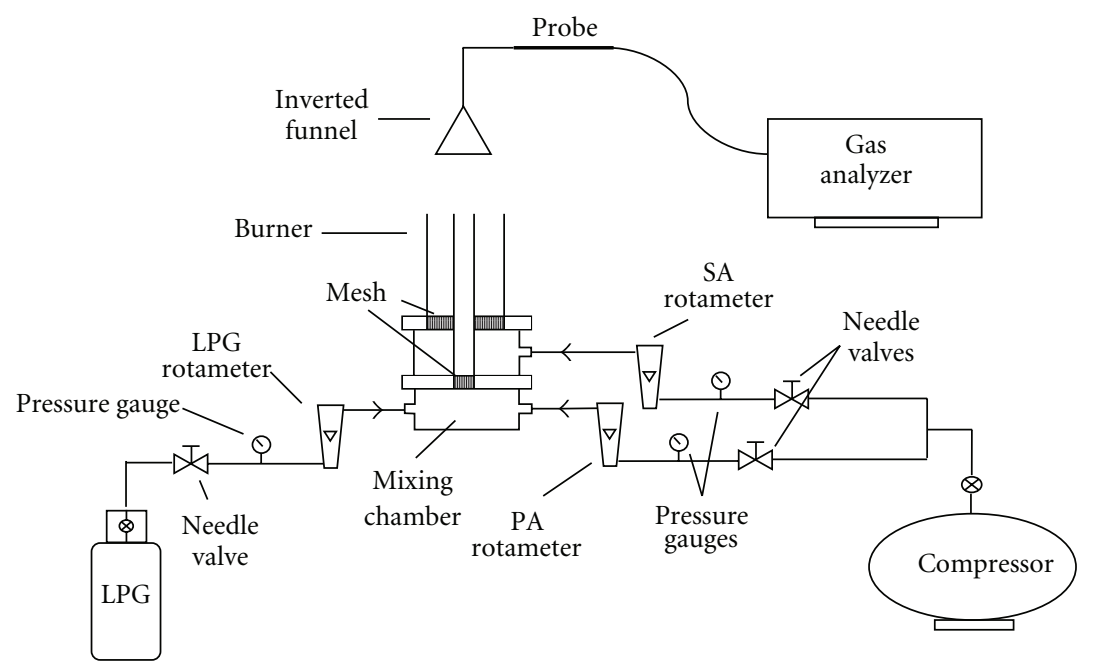

Figure 1: Schematic of the experimental setup.

in induction period of soot formation. Gore and Zhan [4] performed experimental investigations on laminar partially premixed methane air in an overventilated co-flow jet flame. They concluded that, for a fixed fuel flow rate and overall equivalence ratio, an optimum level of partial premixing exists. The effect of partial premixing on turbulent jet flames and the emission characteristics of the same were studied by Lyle et al. [5]. Fuel property of LPG for transportation was reported by Demirbas [6]. Lee and Ryu [7] studied the flame propagation and combustion characteristics in a heavy duty LPG run engine. Laser deflection method and Schlieren photography method were used to measure the flame propagation speed. They reported that the flame propagation speed reached its maximum at the stoichiometric equivalence ratio. Although literatures are available reporting the combustion, and emission characteristics of LPG-air flames, information related to the behavior of flame shapes and extents in a dual stream burner with varying primary and secondary air flow rates have not been investigated in detail. An attempt has been made in this study to carry out such an investigation to explain the flame shapes, variation of flame lengths, flame speed and emission characteristics in a coaxial burner by varying both primary and secondary air at different percentages of stoichiometric air flow rate. The effects of partial premixing are studied here in detail.

\section{Experimental Setup and Procedure}

The schematic of the experimental setup is shown in Figure 1. An axisymmetric co-flow burner with two concentric tubes made of stainless steel is used in the experiments. Metered quantities of LPG and air are supplied from radial inlets to a mixing chamber. The mixture from the chamber is passed through a central core tube having $10 \mathrm{~mm}$ internal diameter. Surrounding this core tube, there is a co-flow tube of $42 \mathrm{~mm}$ internal diameter. Secondary air is supplied through this coflow tube. Fine meshes are placed in the tube to filter eddies. This also helps in intercepting the flame, in case the flame flash backs into the tube.
In this study, the LPG flow rate is kept constant at $22.5 \mathrm{~g} / \mathrm{h}$. For the given flow rate of secondary air, the primary air flow rate is varied from $0 \%$ to $86 \%$ of the stoichiometric air flow rate. The effect of secondary air on the flame characteristics is also studied by changing its flow rate between $100 \%, 150 \%$, and $200 \%$ of the stoichiometric air. Air supply has been taken from a compressor storage tank. Controlling of the upstream pressure in the air line is done by a pressure regulator. An inverted funnel arrangement is kept above the burner, without disturbing the flame to collect the hot gases from the flame. The hot gas is subsequently analyzed using Kane KM9106 Quintox gas analyzer for the concentrations of $\mathrm{CO}, \mathrm{CO}_{2}$, and NO. The gas analyzer is having an autocalibration setup during every startup. The maximum values of the species concentration that can be measured are $10 \%, 20 \%$, and $5000 \mathrm{ppm}$, for $\mathrm{CO}, \mathrm{CO}_{2}$, and $\mathrm{NO}$, respectively. The resolution is $0.01 \%$ and $1 \mathrm{ppm}$, and the accuracy being $\pm 5 \%$. Once the flame is stabilized, the gas analyzer is allowed to reach steady state for around 60 to 90 seconds, and the species concentrations are noted down. The above procedure is repeated at least 5 times for all the cases. The variation has been observed to be within $\pm 1.5 \%$. High definition instantaneous digital photographs are taken at each set of readings with high-resolution digital camera. These photographs are used to visualize and analyze the flame shape and sizes. Soot inception points, length of blue region in the flame, flame diameter variation through the length of the flame, and cone angle are investigated with the help of Image J software.

\section{Results and Discussion}

3.1. Effect of Primary and Secondary Air Flow Rates on Flame Shapes and Visible Structure. The digital images of flames for different primary and secondary air flow rates are presented in Figure 2. The effect of partial premixing and the co-flow secondary air on the flame shapes can be clearly seen from the varying flame images. In a pure co-flow diffusion flame case $(0 \%$ PA, Figure $2(\mathrm{a}))$, near the burner exit, the flame 


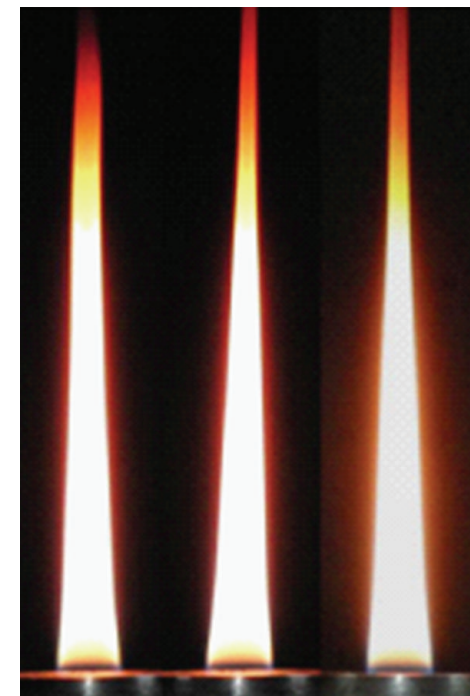

(a) $0 \% \mathrm{PA}$

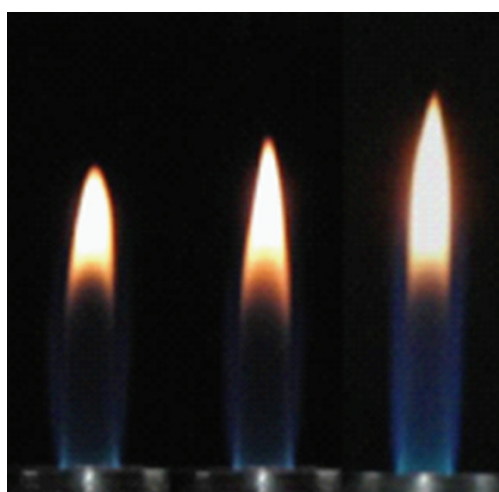

(d) $50 \% \mathrm{PA}$

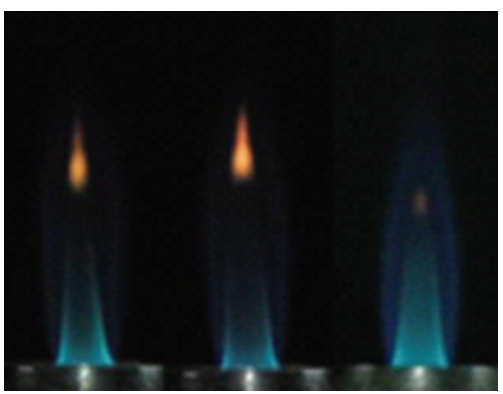

(g) $80 \% \mathrm{PA}$

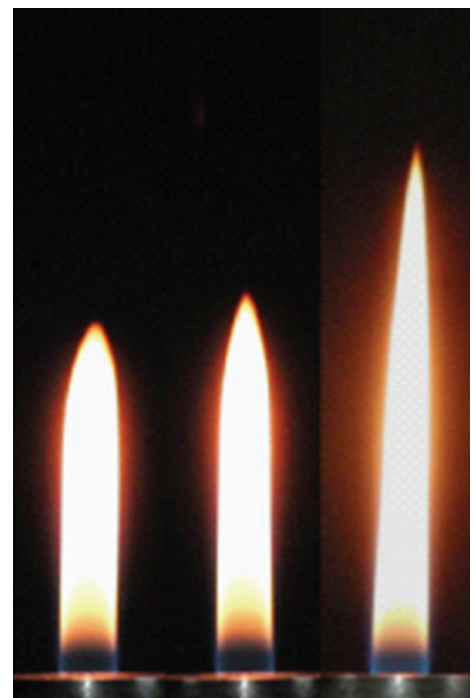

(b) $20 \% \mathrm{PA}$

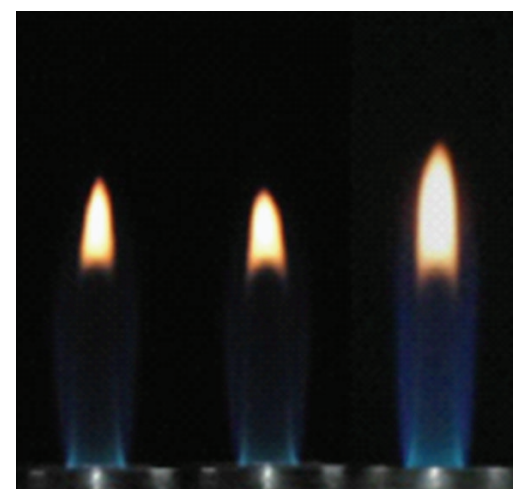

(e) $60 \% \mathrm{PA}$

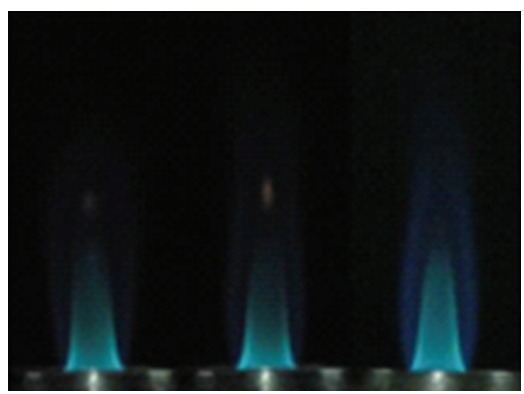

(h) $83 \% \mathrm{PA}$

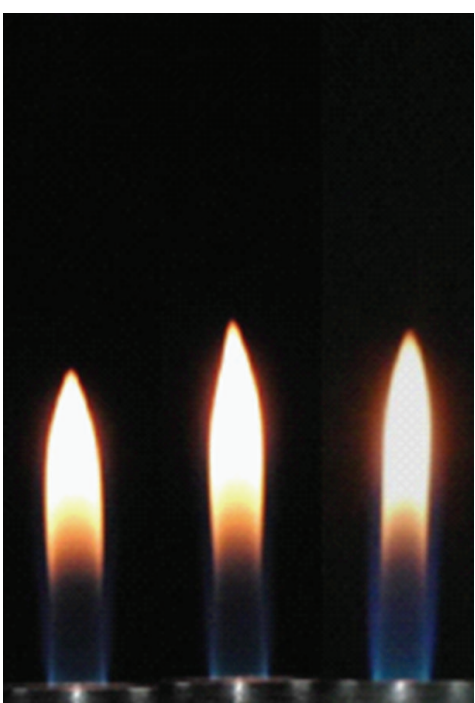

(c) $40 \% \mathrm{PA}$

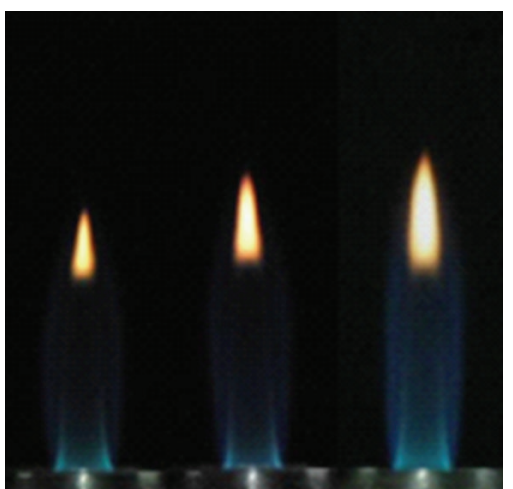

(f) $70 \% \mathrm{PA}$

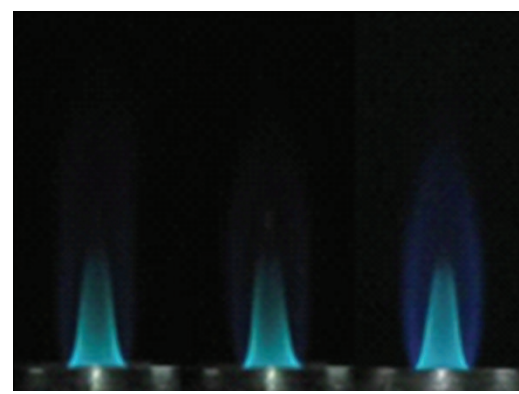

(i) $86 \% \mathrm{PA}$

Figure 2: Flame images: (a) 0\% PA, (b) 20\% PA, (c) 40\% PA, (d) 50\% PA, (e) 60\% PA, (f) 70\% PA, (g) $80 \%$ PA, (h) $83 \%$ PA, and (i) $86 \%$ PA. Left, middle, and right photos in each indicates $100 \%$ SA, $150 \%$ SA, and $200 \%$ SA, respectively.

has a very little bluish color region indicating proper mixing of the fuel with the entraining coflowing air. Luminous flame radiation (bright yellow color) is observed along the length of the flame. Near to the flame tip, the color transits from bright yellow to orange and further to reddish black colors. These are due to inception, agglomeration, and escape of soot particles. When the fuel is added with a primary air flow rate of $20 \%$ of the stoichiometric air flow rate, the length of the bluish region at the bottom is seen to increase (Figure 2(b)).
The luminous characteristics remain almost the same. When the secondary co-flow air flow rate is increased at a given $\% \mathrm{PA}$, a flame is seen to elongate, and its radius slightly reduces. This is due to the increase in the velocity of the secondary air which tries to stretch the flame in the axial direction. The soot inception point also moves further to the downstream of the flame (Figure 3). When the primary air flow is increased to $40 \%$ (Figure 2(c)) of the stoichiometric air flow rate, a significant decrease in the flame height is 


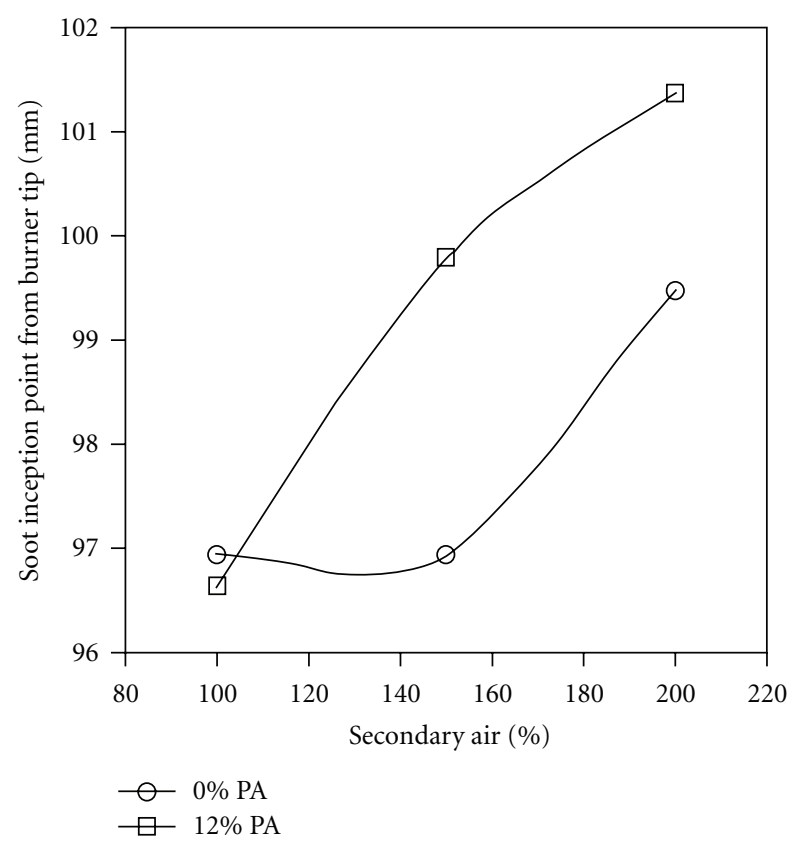

FIGURE 3: Variation of soot inception point measured from the burner tip.

observed. The extent of the bluish premixed flame region increases significantly, and the orange and reddish black zones near the flame tip are now almost absent.

When the primary air flow rate is increased to $50 \%$ and further to $60 \%$ of the stoichiometric value (Figures $2(\mathrm{~d}$ ) and 2 (e), resp.), premixed flame zone is observed near the burner exit with an outer bluish-colored diffusion mantle. The flame height further decreases. At $60 \% \mathrm{PA}$, when the secondary air flow rate is increased to $200 \%$ of the stoichiometric flow rate, the color of the flame near the burner becomes greenish blue. Further increase in the primary air to $70 \%$ of the stoichiometric air flow rate results in an increase in the length of inner premixed flame zone (Figure 2(f)). But the overall flame height remains comparable to the $60 \%$ PA case. The luminosity of the flame decreases significantly indicating an almost complete oxidation of soot. A bright bluish-green inner cone zone with a small luminous zone at its tip is seen and is surrounded by a blue diffusion mantle. As the primary air is increased to $80 \%$ (Figure $2(\mathrm{~g})$ ), the luminous zone becomes dull and almost vanishes. In general, a cone-shaped, bright blue color inner premixed flame zone is formed, with a faint orange-colored tip. At the highest secondary flow rate of $200 \%$ of stoichiometric air, the orange color tip almost fades out. The characteristic of the flame becomes comparable to a rich premixed flame in a coaxial air stream. A further increase of the primary air flow rate to $83 \%$ (Figure $2(\mathrm{~h})$ ) the orange region almost disappears even for low secondary air flow rates of $100 \%$ and $150 \%$ of stoichiometric air flow rates. A bright blue inner premixed flame zone is clearly observed. A same trend is observed at $86 \%$ PA (Figure 2(i)). The length of the visible blue region has been measured by image processing the photograph in software Image J as mentioned earlier. The visible burner

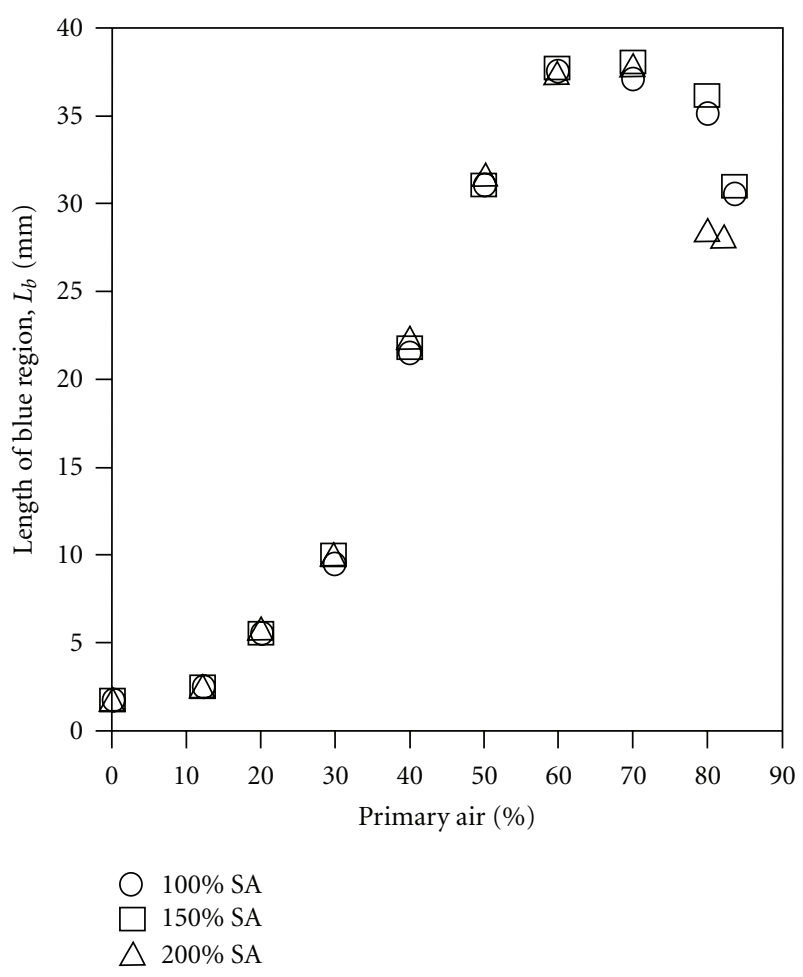

FIGURE 4: Variation of the length of blue region.

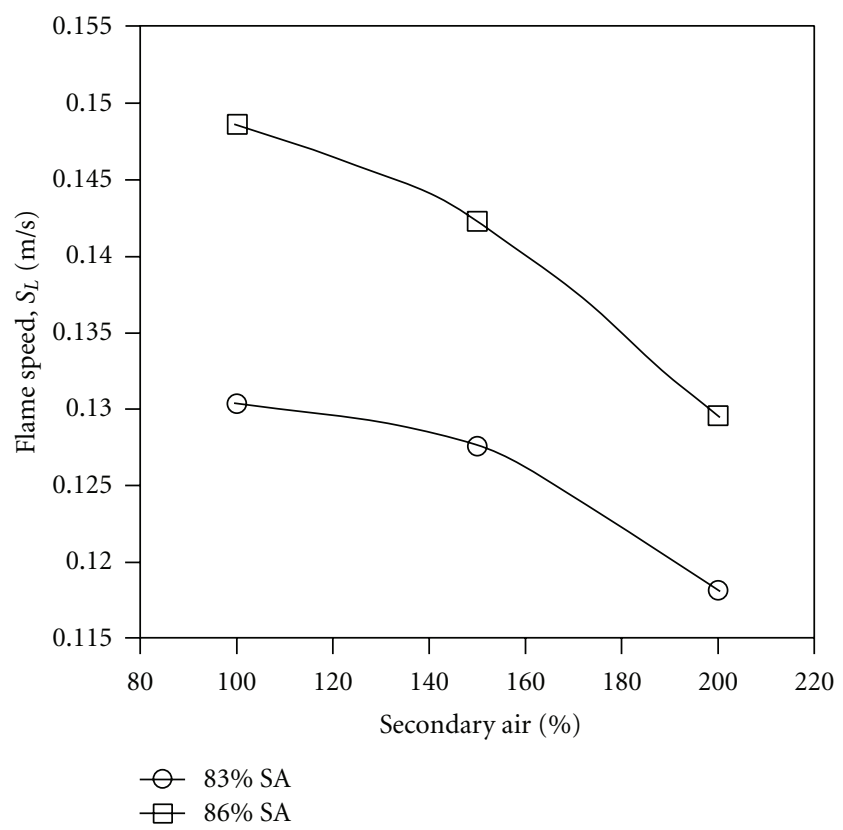

FIgURE 5: Variation of the flame speed.

diameter has been kept as the reference scale for translating number of pixels to flame dimensions.

The length of the blue region in the flame is found to increase with increase in \% PA, until the inner premixed zone is formed around 70\% PA. After that, it decreases due to increased availability of oxidizer in the primary mixture. This trend is shown in Figure 4. In the increasing blue length 


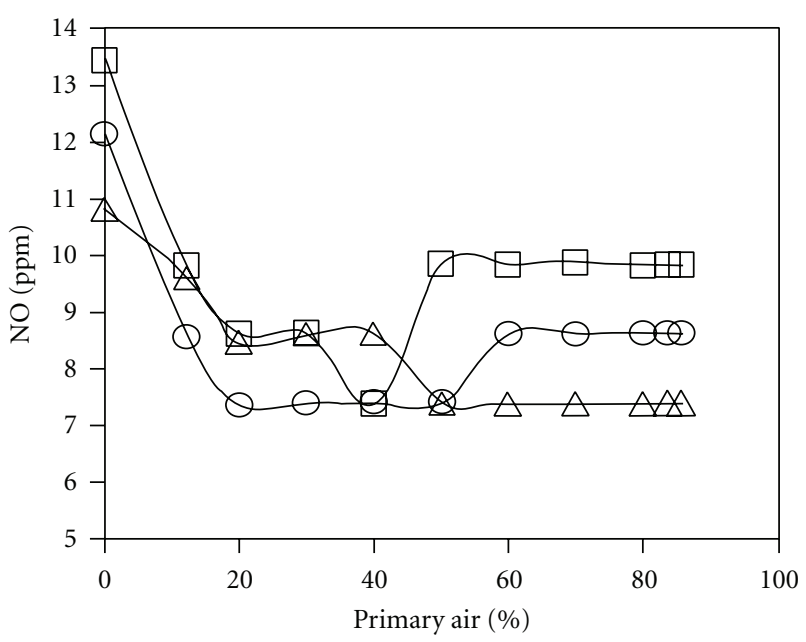

(a)

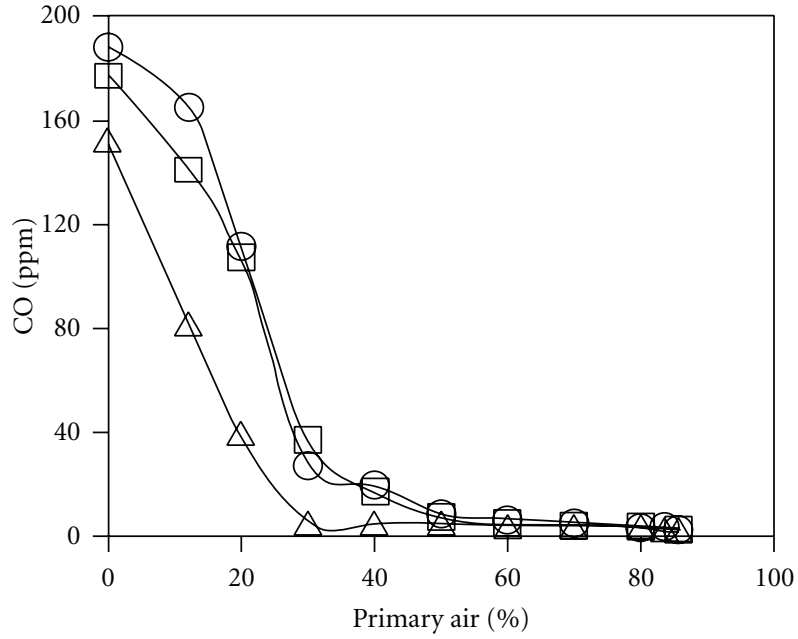

(b)

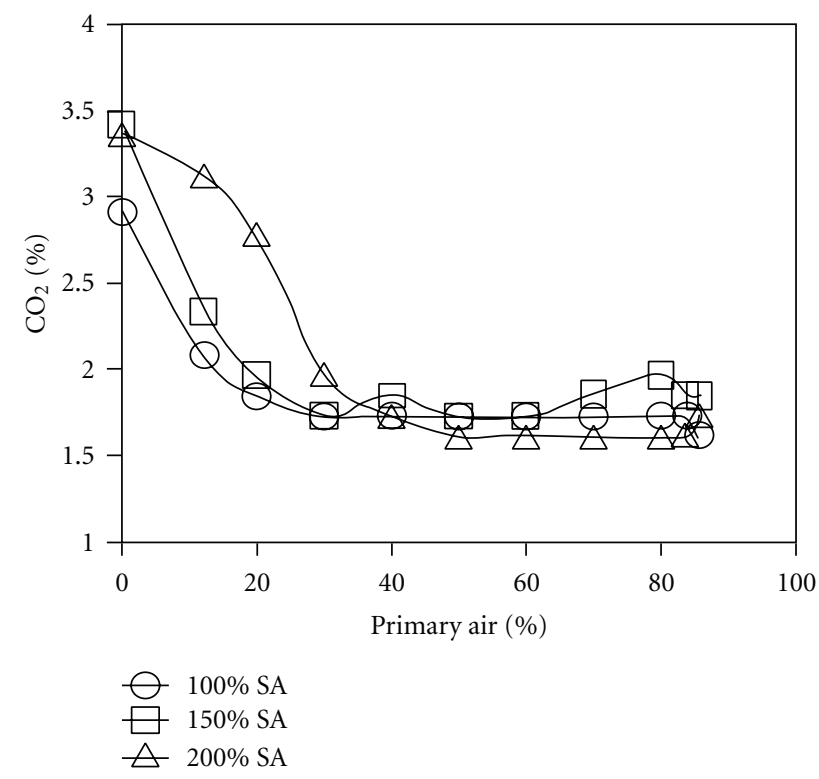

(c)

Figure 6: Variation of flue gas species: (a) $\mathrm{CO}$ (ppm), (b) $\mathrm{CO}_{2}(\%)$, and (c) $\mathrm{NO}$ (ppm).

regime, the effect of the secondary air on the length of blue region is seen to be negligible as enough air becomes available to initially entrain and mix with the fuel jet.

For the cases of $83 \% \mathrm{PA}$ and $86 \% \mathrm{PA}$, where the inner premixed flame cone is observed, the laminar flame speed has been approximately calculated using the half-cone angle extracted from the digital image, for the purpose of relative comparison. An increase in the flame speed is observed with an increase in \% PA, and a decrease in the flame speed is obtained with an increase in the secondary air flow rate (Figure 5). This is due to the combined effect of \% PA and secondary air, which results in corresponding change in the overall equivalence ratio. The lower values of the laminar flame speed are due to dilution of the mixture by the coflowing secondary air.
3.2. Effect of Primary and Secondary Air Flow Rates on Emissions from the Flame. The concentrations of species such as $\mathrm{CO}, \mathrm{CO}_{2}$, and $\mathrm{NO}$ from the burner are measured using a portable gas analyzer. The gas analyzer also provides the oxygen concentration in volumetric $\%$, which has been excluded, and the concentration of other species has been recalculated to avoid dilution effects from varying primary and secondary air flow rates. Temperature of the flue gas at the probe tip is recorded to be around $307 \mathrm{~K}$. The variations of individual species are plotted against \% PA. Variations of emissions with secondary air flow rates are also compared in the same plot. The concentration of $\mathrm{CO}$ (in ppm) displays a decreasing trend with increasing \% PA (Figure 6(a)) till a value of 40\%. It almost remains constant for further increase in \% PA above $40 \%$. The CO concentration decreases considerably with an 
increase in secondary air flow till $40 \%$ PA. These are due to increased availability of air which enhances oxidation of $\mathrm{CO}$ to $\mathrm{CO}_{2}$. The effect of increasing the secondary air for primary air supply more than $50 \%$ is found to be less significant as very little $\mathrm{CO}$ is observed. The volumetric percentage of carbon-dioxide variation is plotted in Figure 6(b). Initially $\mathrm{CO}_{2}$ concentration decreases with increasing \% PA until around $40 \%$ as in $\mathrm{CO}$ case. In this range, with the addition of secondary air flow, the $\mathrm{CO}_{2}$ concentration increases due to additional oxidation of $\mathrm{CO}$. The variations of $\mathrm{CO}$ and $\mathrm{CO}_{2}$ show that the effect of air premixing on characteristics of flames almost ceases after the \% PA reaches a value of approximately $50 \%$ for this co-flow configuration. The NO concentration, which is generally very low for this system, is found to decrease initially with increasing primary air, and it reaches a minimum value around 40\%-50\% PA and remains almost the same after that (Figure 6(c)). Interestingly, in the range of \% PA between $50 \%$ and $86 \%$, NO increases with the increase in secondary air from $100 \%$ to $150 \%$, and then it decreases rapidly as \% SA increases to $200 \%$, lower than the value at $100 \%$ SA. While the CO oxidation is favored with increasing primary and secondary air flow rates, NO production depends on both oxygen availability and the temperature of the reaction zone. The combined effects of increased CO oxidation and reduced temperature for 200\% $\mathrm{SA}$ have resulted in a significant decrease in NO for that case.

\section{Conclusions}

The characteristic of LPG-air partially premixed flames is analyzed in this paper. A co-flow burner with premixed reactants in the central core and air in the annular region is employed. At zero and low percentages of primary air, the point of soot inception from the burner tip increases with the increase in the secondary air flow rate. For a given primary air flow rate, a marginal increment in the length of blue region in the flame is observed with the increase in the secondary air. At higher values of \% PA, addition of secondary air tends to decrease the flame speed. With increasing air premixing in the core flow, the $\mathrm{CO}$ concentration decreases initially and almost remains constant for \% PA equal to $40 \%$ and above. Increase of the secondary air also results in steeper reduction of $\mathrm{CO}$ concentration at lower primary air flows. The concentration of carbon dioxide increases with the increase in the primary and secondary air flow rate indicating oxidation of $\mathrm{CO}$. The variation of $\mathrm{NO}$ suggests that a minimum $\mathrm{NO}$ is attained around \% PA values between $40 \%$ and $50 \%$. These indicate that in a dual air stream configuration such as in this study, that partial premixing is optimum around \% PA value of around 45\% as it gives lower emissions and higher flame stability for LPG-air flames.

\section{References}

[1] D. P. Mishra and A. Rahman, "An experimental study of flammability limits of LPG/air mixtures," Fuel, vol. 82, no. 7, pp. 863-866, 2003.

[2] D. P. Mishra, "Stability and emission in a LPG-Air premixed coaxial jet flame burner under a wide range of operating con- ditions," International Journal of Chemical Reactor Engineering, vol. 7, article A64, 2009.

[3] D. P. Mishra and P. Kumar, "Experimental investigation of laminar LPG- $\mathrm{H}_{2}$ jet diffusion flame with preheated reactants," Fuel, vol. 87, no. 13-14, pp. 3091-3095, 2008.

[4] J. P. Gore and N. J. Zhan, " $\mathrm{NO}_{\mathrm{x}}$ emission and major species concentrations in partially premixed laminar methane/air coflow jet flames," Combustion and Flame, vol. 105, no. 3, pp. 414427, 1996.

[5] K. H. Lyle, L. K. Tseng, J. P. Gore, and N. M. Laurendeau, "A study of pollutant emission characteristics of partially premixed turbulent jet flames," Combustion and Flame, vol. 116, no. 4, pp. 627-639, 1999.

[6] A. Demirbaş, "Fuel properties of hydrogen, liquefied petroleum gas (LPG), and compressed natural gas (CNG) for transportation," Energy Sources, vol. 24, no. 7, pp. 601-610, 2002.

[7] K. Lee and J. Ryu, "An experimental study of the flame propagation and combustion characteristics of LPG fuel," Fuel, vol. 84, no. 9, pp. 1116-1127, 2005. 

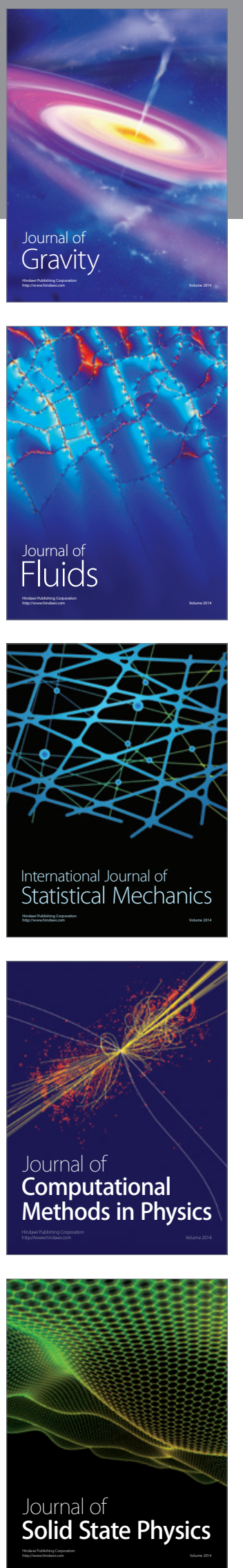
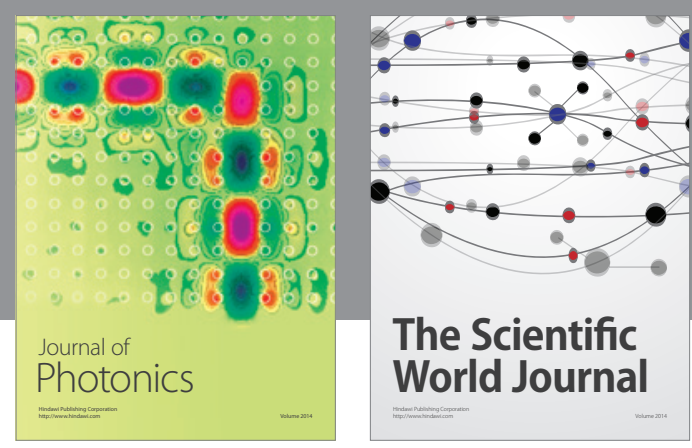

The Scientific World Journal

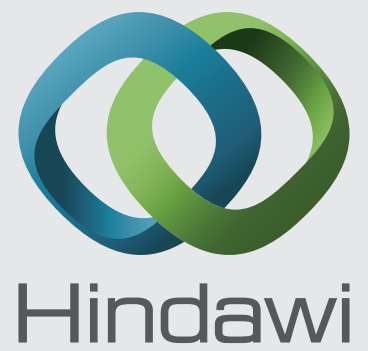

Submit your manuscripts at http://www.hindawi.com
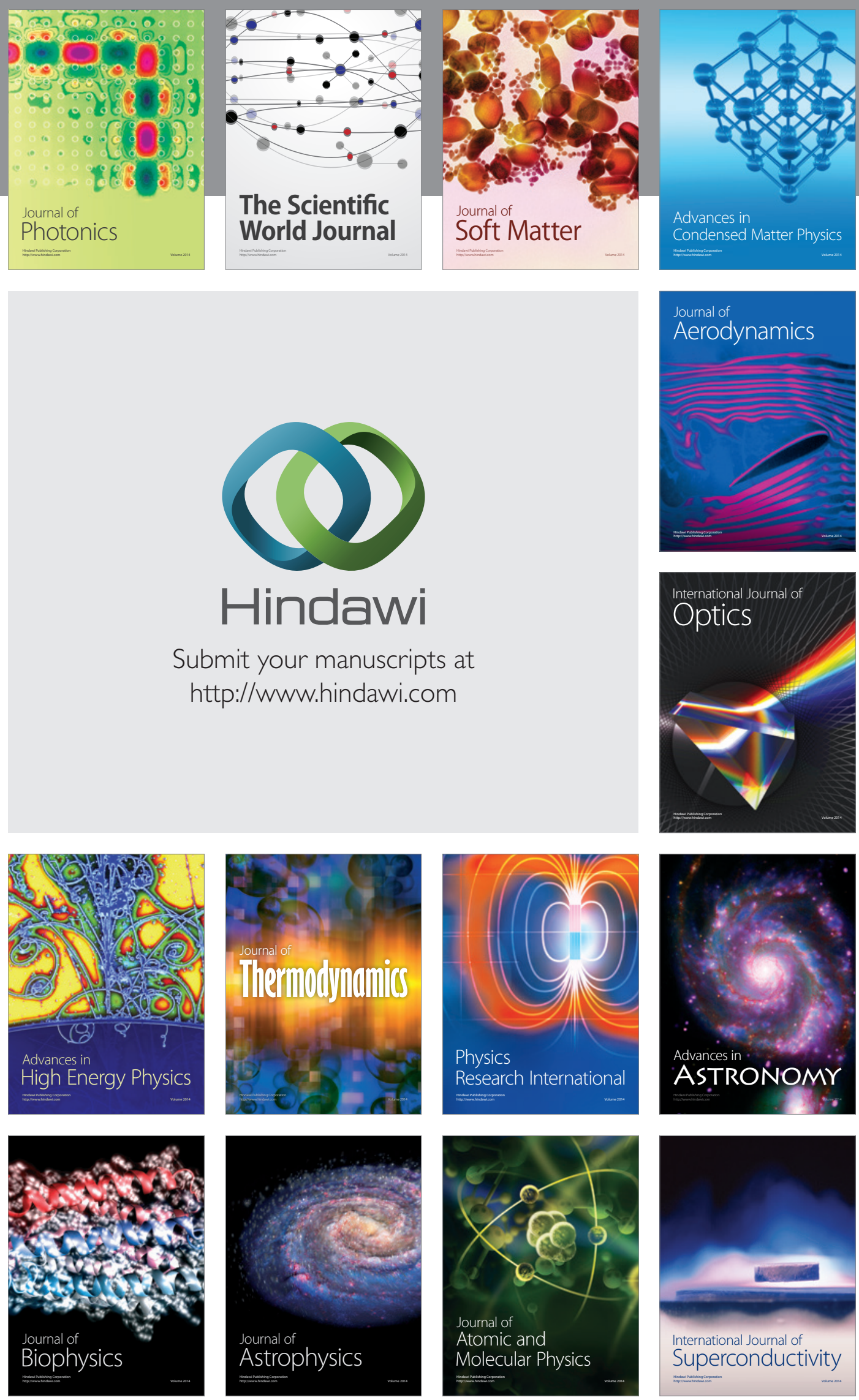
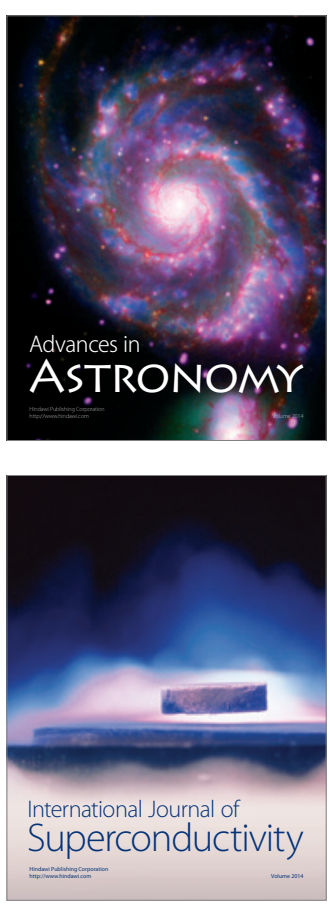